\title{
High pretreatment plasma D-dimer levels predict poor survival in patients with diffuse large B-cell lymphoma in the real world
}

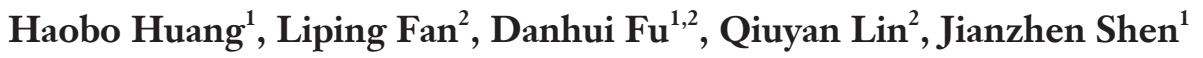 \\ ${ }^{1}$ Department of Hematology, Fujian Institute of Hematology, Fujian Provincial Key Laboratory on Hematology, Fujian Medical Center of \\ Hematology, Fujian Medical University Union Hospital, Fuzhou, China; ${ }^{2}$ Department of Blood Transfusion, Fujian Medical University Union \\ Hospital, Fuzhou, China \\ Contributions: (I) Conception and design: H Huang, J Shen; (II) Administrative support: J Shen, D Fu; (III) Provision of study materials or patients: J \\ Shen, D Fu, H Huang; (IV) Collection and assembly of data: H Huang, L Fan, Q Lin; (V) Data analysis and interpretation: H Huang, J Shen, D Fu, \\ L Fan; (VI) Manuscript writing: All authors; (VII) Final approval of manuscript: All authors. \\ Correspondence to: Jianzhen Shen. Department of Hematology, Fujian Institute of Hematology, Fujian Provincial Key Laboratory on Hematology, \\ Fujian Medical Center of Hematology, Fujian Medical University Union Hospital, Fuzhou 350001, China. Email: doctorsjz@163.com.
}

Background: Data on the role of pretreatment plasma D-dimer levels in the prognostic prediction of patients with diffuse large B-cell lymphoma (DLBCL) are limited. We here studied the potential prognostic roles of pretreatment plasma D-dimer levels in patients with DLBCL.

Methods: We retrospectively analyzed medical records of 308 newly diagnosed patients with DLBCL admitted to the Fujian Medical University Union Hospital between January 2011 and December 2018. Receiver operating characteristic (ROC) curve analysis were used to generate an optimal cut-off value for pretreatment plasma D-dimer levels in patients with DLBCL. According to the cut-off value, all patients were divided into the low D-dimer and high D-dimer groups. We analyzed the relationship between pretreatment plasma D-dimer levels and clinical and laboratory characteristics in patients with DLBCL. Univariate and multivariate analyses were used to assess prognostic factors for overall survival (OS) and progression-free survival (PFS).

Results: Patients with B symptoms, plasma lactate dehydrogenase levels >upper limit of normal (ULN), poor Eastern Cooperative Oncology Group score (2 to 4), advanced stage (III-IV), >1 extranodal site, higher International Prognostic Index (IPI) (2 to 5) and higher National Comprehensive Cancer Network IPI (NCCN-IPI) $(\geq 4)($ all $\mathrm{P}<0.001)$ had higher pretreatment plasma D-dimer levels $(\geq 1.4 \mu \mathrm{g} / \mathrm{mL})$. Patients with higher plasma D-dimer levels had worse OS and $\mathrm{PFS}(\mathrm{P}<0.001$ and $\mathrm{P}=0.001$, respectively).

Conclusions: Higher pretreatment plasma D-dimer level was associated with poor survival and was an independent poor predictor of OS among untreated patients with DLBCL.

Keywords: D-dimer; diffuse large B-cell lymphoma (DLBCL); prognostic factor

Submitted Sep 19, 2020. Accepted for publication Jan 29, 2021.

doi: $10.21037 /$ tcr-20-2908

View this article at: http://dx.doi.org/10.21037/tcr-20-2908

\section{Introduction}

Diffuse large B-cell lymphoma (DLBCL) is the commonest type of non-Hodgkin lymphoma (NHL) and accounts for $30-40 \%$ of all NHL cases worldwide (1). Owing to its heterogeneity, the prognosis of DLBCL varies. After undergoing standard initial treatment (such as the R-CHOP-21 regimen), 40-50\% of patients with DLBCL experience refractory disease or relapse $(2,3)$. Therefore, the outcome of DLBCL should be predicted at the time of diagnosis to guide the intensity of subsequent treatment among patients with DLBCL.

The International Prognostic Index (IPI) consisting of age, Ann Arbor staging, serum lactate dehydrogenase (LDH) level, performance status, and the number of 
extranodal disease sites was used to predict the outcomes of patients with DLBCL. However, the IPI cannot accurately discriminate the outcomes of all patients with DLBCL. Several parameters extracted from clinical characteristics or laboratory examination were added to this index to improve its prognostic efficiency; however, the precision of this modified index remains controversial. Therefore, it is necessary to identify other factors to be extracted from patients with DLBCL to provide additional information for prognostication.

Abnormal forms of coagulation characterized by hypercoagulation caused by cancer cells are found in many cancer types. Cancer-associated thrombosis occurs secondary to hyperfibrinogenemia or low levels of fibrinolysis. Factors involved in coagulation and fibrinolysis were reported to contribute to the proliferation, migration, and invasion of cancer cells (4-8).

D-dimer, is a specific product of fibrin degradation. Several studies have shown that elevated pretreatment plasma D-dimer levels were predictors of poor survival in various types of solid tumor (9-15). However, only few studies have assessed the prognostic role of pretreatment plasma D-dimer level in DLBCL $(16,17)$. Thus, we retrospectively analyzed data of patients with DLBCL at our hospital, aiming to explore the relationship between pretreatment plasma D-dimer levels and the prognosis of patients with DLBCL and to evaluate the prognostic value of pretreatment plasma D-dimer level. We present the following article in accordance with the REMARK reporting checklist (available at http://dx.doi.org/10.21037/ tcr-20-2908).

\section{Methods}

\section{Patient selection}

The medical information of newly diagnosed patients with DLBCL was reviewed and collected at Fujian Medical University Union Hospital from 1 January 2011 to 31 December 2018. The inclusion criteria were as follows: (I) diagnoses made via tissue biopsy or surgical excision according to the World Health Organization classification; (II) aged $\geq 14$ years; (III) received no less than 4 cycles of immunochemotherapy; (IV) plasma D-dimer concentrations assessed within seven days before treatment. The exclusion criteria were as follows: (I) diagnosed with primary mediastinal lymphoma or primary central nervous system lymphoma; (II) without sufficient clinical data; (III) known congenital coagulative abnormality; (IV) thromboembolic event or ongoing anticoagulant treatment within 3 months before treatment; (V) known active infection or positive serologic tests for the human immunodeficiency virus; (VI) neurosurgery, pregnancy, or stroke within 6 months before treatment. The study was conducted in accordance with the Declaration of Helsinki (as revised in 2013). This study was approved by the ethics committee of Fujian Medical University Union Hospital (2019KJCX047) and individual consent for this retrospective analysis was waived.

\section{Data collection}

Among all patients included, data regarding age, gender, B symptoms, LDH level, Ann Arbor stage, histopathological diagnosis, imaging findings, bone marrow aspiration biopsy results, performance status, and clinical follow-up were collected. Histopathological diagnosis of DLBCL was classified into germinal center B-cell (GCB) or non-GCB phenotype according to the Hans algorithm (18).

All patients included underwent immunochemotherapy combined with or without surgery as primary therapeutic regimens. Immunochemotherapy consisted of standard CHOP (cyclophosphamide, doxorubicin, vincristine, and prednisone) or CHOP-like (cyclophosphamide, epirubicin, vincristine, and prednisone) regimens combined with rituximab. Response to treatment was evaluated according to the International Working Group response criteria for malignant lymphoma (19). Patients who experienced treatment failure or disease progression or relapse were treated with second-line regimens recommended by the National Comprehensive Cancer Network (NCCN) guidelines (20-22).

Plasma D-dimer levels were assessed using an automatic coagulation analyzer (Stago Co., Paris, France) according to the manufacturer's instructions. Peripheral blood samples were collected from all patients within a week before the primary therapy. Receiver operating characteristic (ROC) curve analysis and the area under the curve (AUC) were used to determine the optimal cut-off value for survival as indicated by $\mathrm{D}$-dimer.

Overall survival (OS) was defined as the period between the date on which the patient started treatment and the date of death or last follow-up. Progression-free survival (PFS) was defined as the period from the date on which the patient started treatment to the date of disease progression, relapse, or death, whichever came first. Deaths from all causes were included. Survival time was measured until June 10, 2019. 


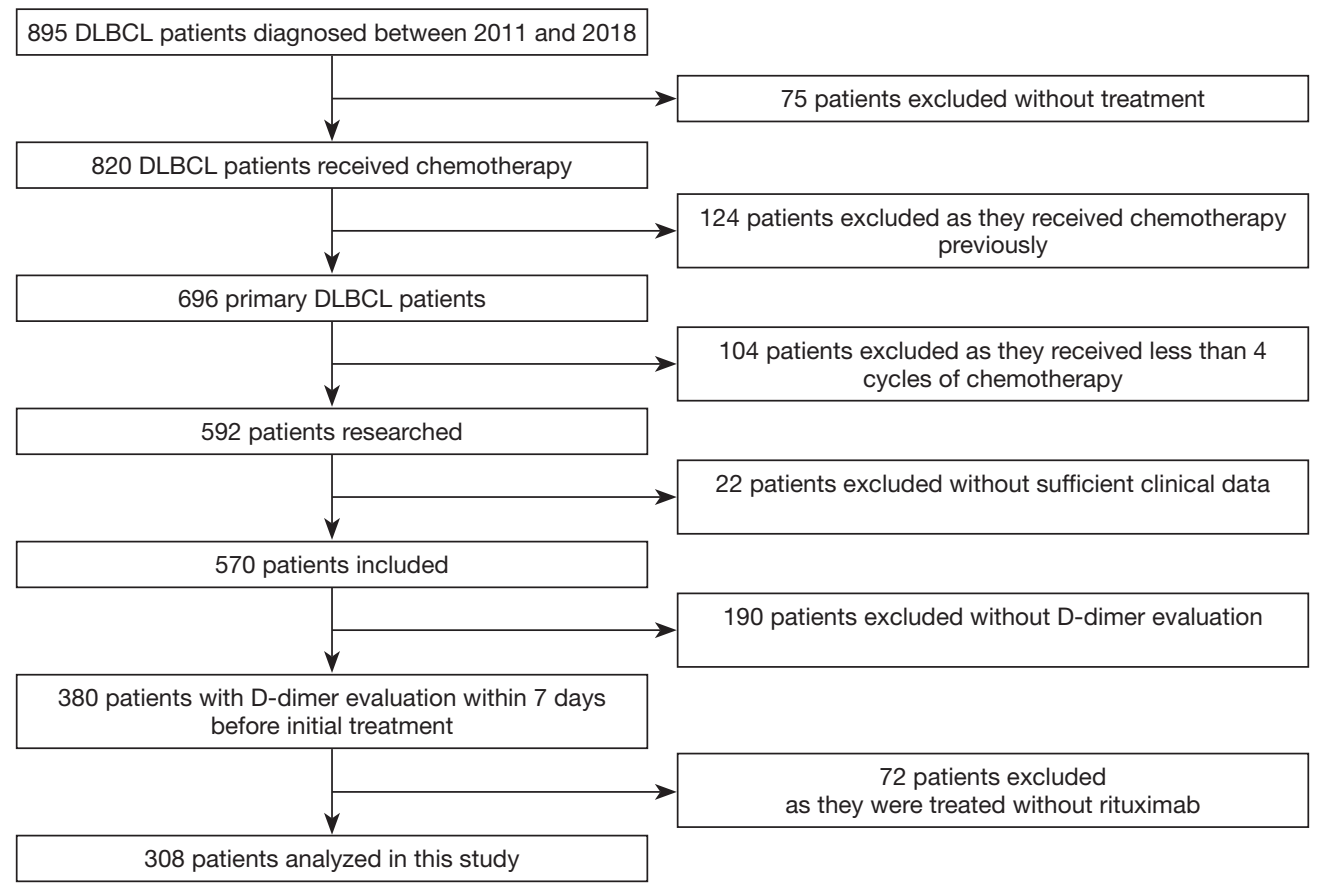

Figure 1 A flowchart showing screening for DLBCL patients.

\section{Statistical analysis}

Continuous and dichotomous variables were compared using the $t$-test and chi-squared test, respectively. Time-toevent data were analyzed using the Kaplan-Meier method. The log-rank test was used to compare the survival times of different groups. The Cox proportional hazards model was used for the univariate analysis of the potential predictors of survival. Variables identified to be significant prognostic factors in the univariate analysis were included in the multivariate analysis using the Cox regression model. All statistical analyses were performed using SPSS version 19.0 for Windows (SPSS Inc., Chicago, IL, USA). Two-tailed P values $<0.05$ were considered statistically significant.

\section{Results}

\section{Patients' characteristics}

A flowchart showing screening for DLBCL patients included was shown as Figure 1. Between January 2011 and December 2018, 308 patients with newly diagnosed DLBCL who met the inclusion criteria were included in the present study. No thrombus event occurred in these patients. The median age of the study cohort at diagnosis was 56 (range, 14-86) years. Pretreatment plasma D-dimer levels among these patients ranged from 0.22 to $>20 \mu \mathrm{g} / \mathrm{mL}$, with a median value of $0.93 \mu \mathrm{g} / \mathrm{mL}$.

\section{Identification of optimal D-dimer cut-off values and patient outcomes}

A ROC curve analysis was used to determine that the optimal cut-off values for D-dimer of OS was $1.4 \mu \mathrm{g} / \mathrm{mL}$, with an AUC value of 0.746 (95\% CI, 0.662-0.829, $\mathrm{P}<0.001$ ) (Figure 2). Then, the patients were divided into two groups, high $(\geq 1.4 \mu \mathrm{g} / \mathrm{mL})$ and low $(<1.4 \mu \mathrm{g} / \mathrm{mL})$ D-dimer level groups, for further analysis. Ninety-six patients had high plasma D-dimer levels and 212 had low levels. The correlation analyses of the relationships between the characteristics of patients with DLBCL and pretreatment plasma D-dimer levels in the study cohort are shown in Table 1. The presence of B symptoms, higher plasma LDH level [> upper limit of normal (ULN)], poor performance status [Eastern Cooperative Oncology Group (ECOG) score 2-4], advanced stage (III-IV), more than 1 extranodal site, higher IPI (2 to 5) and higher NCCNIPI $(\geq 4)$ were associated with higher pretreatment plasma D-dimer levels (Table 1). 


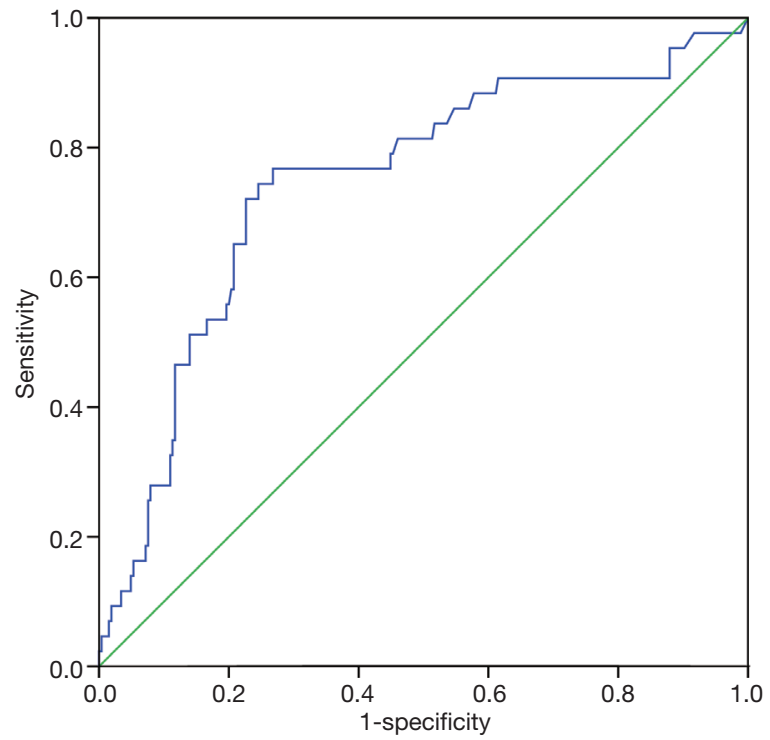

Figure 2 Receiver operating characteristic curve analysis of pretreatment plasma D-dimer levels.

\section{Univariate and multivariate analyses of potential prognostic factors for survival}

The median follow-up period of this cohort was 22.13 (range, 2.73-89.07) months. 43 patients died, and 75 patients were refractory to initial treatment or relapsed after remission during the period of follow-up. The median OS and PFS were not reached in this cohort.

Univariate and multivariate analysis of prognostic factors for OS and PFS of DLBCL patients in this cohort were listed in Tables 2,3. Kaplan-Meier curves of pretreatment plasma D-dimer level for OS and PFS were presented in Figure 3.

\section{Discussion}

In the last decade, with the addition of rituximab to standard chemotherapy, the outcomes of patients with DLBCL have improved dramatically. Meanwhile, the

Table 1 Demographic and clinical characteristics of enrolled patients $(n=308)$

\begin{tabular}{|c|c|c|c|c|}
\hline \multirow{2}{*}{ Characteristics } & \multirow{2}{*}{ Classification } & \multicolumn{2}{|c|}{ D-dimer level, n (\%) } & \multirow[t]{2}{*}{$P$} \\
\hline & & Low $(n=212)$ & High $(n=96)$ & \\
\hline \multirow[t]{2}{*}{ Age (years) } & $>60$ & 71 (33.49) & $38(39.58)$ & 0.306 \\
\hline & $\leq 60$ & $141(66.51)$ & $58(60.42)$ & \\
\hline \multirow[t]{2}{*}{ Gender } & Male & 127 (59.91) & $63(65.63)$ & 0.377 \\
\hline & Female & 85 (40.09) & $33(34.37)$ & \\
\hline \multirow{2}{*}{ B symptoms } & Absent & 174 (82.08) & $52(54.17)$ & $<0.001$ \\
\hline & Present & 38 (17.92) & $44(45.83)$ & \\
\hline \multirow[t]{2}{*}{ LDH } & $>$ ULN & $72(33.96)$ & $72(75.00)$ & $<0.001$ \\
\hline & Normal & $140(66.04)$ & $24(25.00)$ & \\
\hline \multirow[t]{2}{*}{ ECOGscore } & $0-1$ & $175(82.55)$ & $59(61.46)$ & $<0.001$ \\
\hline & $2-4$ & $37(17.45)$ & $37(38.54)$ & \\
\hline \multirow[t]{2}{*}{ Ann Arbor stage } & $|-| \mid$ & $98(46.23)$ & 19 (19.79) & $<0.001$ \\
\hline & III-IV & $114(53.77)$ & $77(80.21)$ & \\
\hline Extranodal & $>1$ & $50(23.58)$ & $53(55.21)$ & $<0.001$ \\
\hline disease & $\leq 1$ & $162(76.42)$ & $43(44.79)$ & \\
\hline \multirow[t]{4}{*}{$\mid \mathrm{PI} \mathrm{I}^{8}$} & Low risk (score 0-1) & $109(51.42)$ & $15(15.63)$ & $<0.001$ \\
\hline & Low-intermediate risk (score 2) & $45(21.23)$ & $22(22.92)$ & \\
\hline & High-intermediate risk (score 3) & $39(18.40)$ & $26(27.08)$ & \\
\hline & High risk (score 4-5) & $19(8.96)$ & $33(34.38)$ & \\
\hline
\end{tabular}

Table 1 (continued) 
Table 1 (continued)

\begin{tabular}{|c|c|c|c|c|}
\hline Characteristics & Classification & \multicolumn{2}{|c|}{ D-dimer level, n (\%) } & $\mathrm{P}$ \\
\hline \multirow[t]{3}{*}{ NCCN-IPI $\left.\right|^{\&}$} & Low risk (score $0-1$ ) & $57(26.89)$ & $8(8.33)$ & $<0.001$ \\
\hline & Low-intermediate risk (score 2-3) & $99(46.70)$ & $29(30.21)$ & \\
\hline & High-intermediate risk (score 4-5) & 45 (21.23) & $40(41.67)$ & \\
\hline \multirow[t]{3}{*}{ Subtype ${ }^{\&}$} & GCB & $88(41.51)$ & 32 (33.33) & 0.199 \\
\hline & non-GCB & $115(54.25)$ & $62(64.58)$ & \\
\hline & Undetermined & $9(4.25)$ & $2(2.08)$ & \\
\hline
\end{tabular}

\&, the mantissa of two digit is now the result. The mantissa of three digits adds up to 100\%. LDH, lactate dehydrogenase; ULN, upper limit of normal; ECOG, Eastern Cooperative Oncology Group; IPI, International Prognostic Index; GCB, germinal center B-cell.

Table 2 Univariate and multivariate analyses of prognostic factors for OS among patients with DLBCL

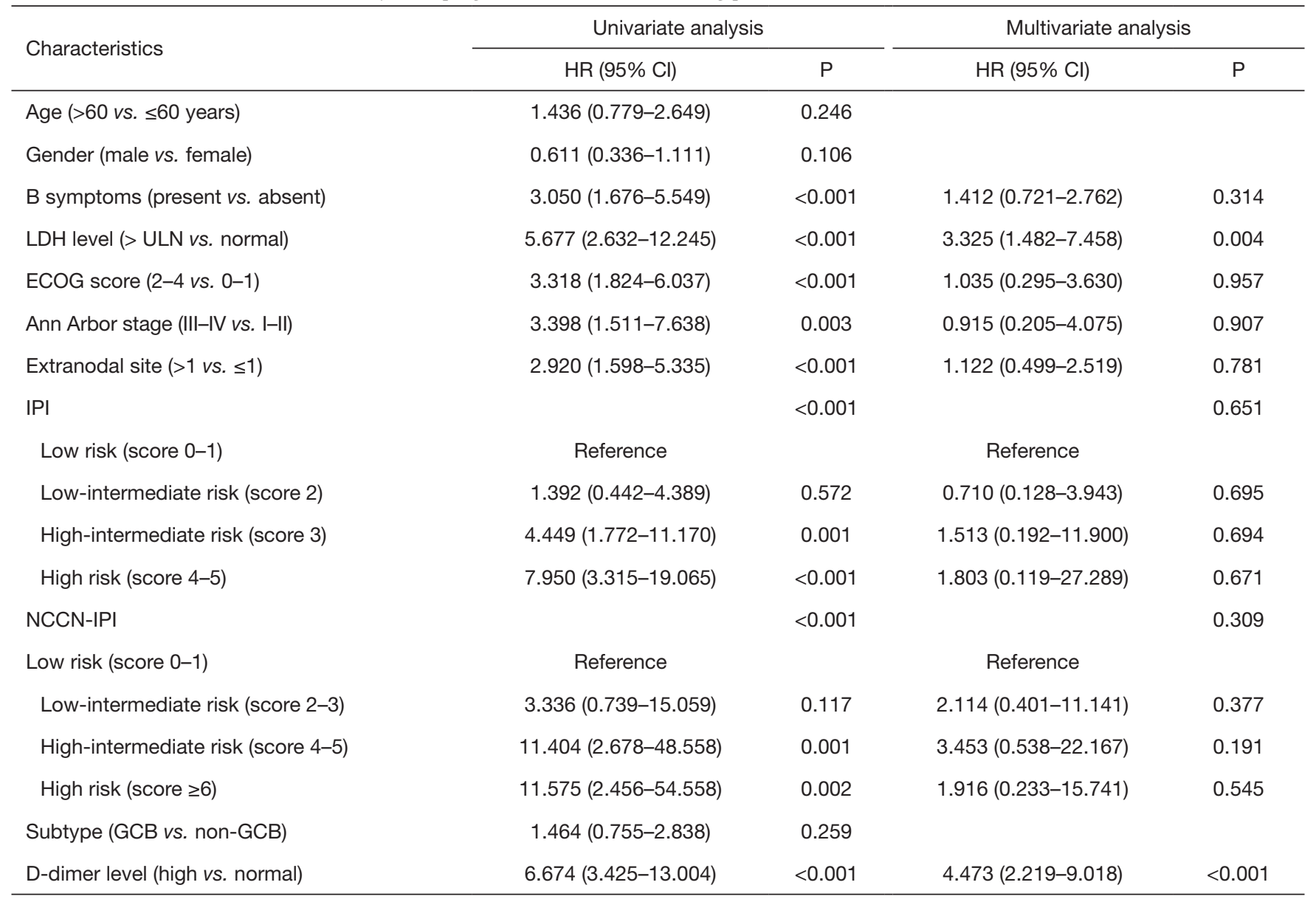

LDH, lactate dehydrogenase; ECOG, Eastern Cooperative Oncology Group; IPI, International Prognostic Index; GCB, germinal center B-cell; $\mathrm{HR}$, hazard ratio; $\mathrm{Cl}$, confidence interval. 
Table 3 Univariate and multivariate analyses of prognostic factors for PFS among patients with DLBCL

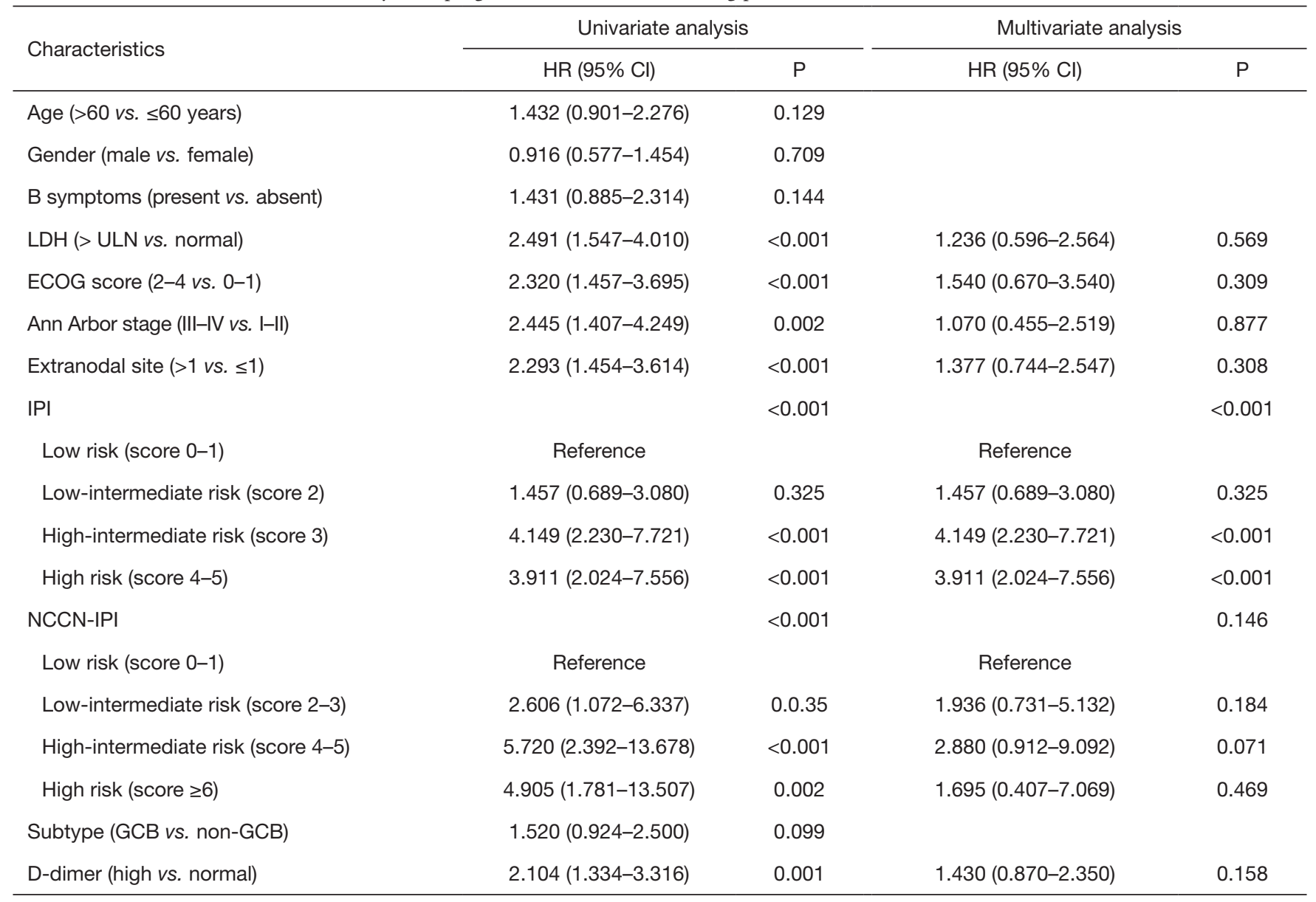

LDH, lactate dehydrogenase; ECOG, Eastern Cooperative Oncology Group; IPI, International Prognostic Index; GCB, germinal center B-cell; $\mathrm{HR}$, hazard ratio; $\mathrm{Cl}$, confidence interval.

efficiency of IPI in prognostic prediction among patients with DLBCL has declined. Thus, experts modified the IPI to R-IPI and NCCN-IPI by adjusting or refining factors included previously $(23,24)$. Other researchers added some clinicopathological characteristics to IPI to constitute new prognostic indicators (25-27). However, the efficiencies of these new indicators in prognostic prediction remain controversial $(25,28-31)$.

$\mathrm{D}$-dimer is a fibrin degradation product. Several studies have shown that higher pretreatment plasma D-dimer level was a poor prognostic factor for lung cancer, colorectal cancer, breast cancer, and so on (9-15). However, data regarding pretreatment plasma $\mathrm{D}$-dimer levels among untreated patients with DLBCL are limited, and its role in determining the prognosis of DLBCL remains controversial. Liu et al. found that higher pretreatment plasma D-dimer level was negatively associated with OS and an independent prognostic factor for worse OS among untreated patients with DLBCL (17). Geng et al. found that higher pretreatment plasma D-dimer level was associated with some clinicopathological factors, such as advanced Ann Arbor stage (III-IV) and high LDH level (> ULN), and was negatively associated with OS, but was not an independent poor prognostic factor among untreated patients with DLBCL (16).

In the present study, we assessed the roles of D-dimer and other potential prognostic factors on survival among untreated patients with DLBCL. At first, we determined the optimal cut-off value of pretreatment plasma D-dimer level, according to the OS of patients with DLBCL using ROC curve analysis. The optimal cut-off value was $1.4 \mu \mathrm{g} / \mathrm{mL}$. Then we found that higher pretreatment plasma D-dimer level $(\geq 1.4 \mu \mathrm{g} / \mathrm{mL})$ was associated with the presence of B-cell lymphoma symptoms, higher plasma 

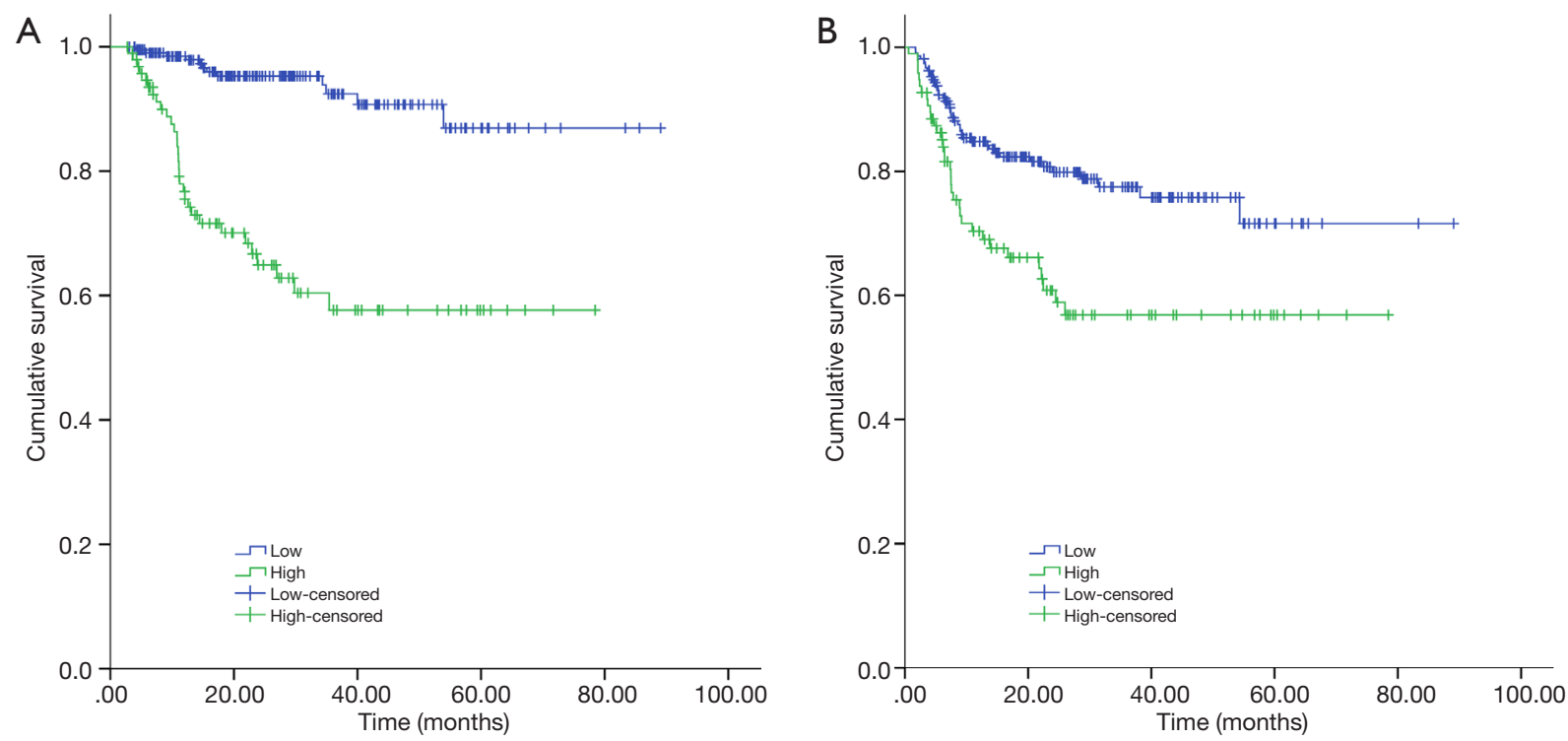

Figure 3 Kaplan-Meier curves of OS (A) and PFS (B) according to pretreatment plasma D-dimer level. (A) Patients with low pretreatment plasma D-dimer level had longer OS than patients with high pretreatment plasma D-dimer level $(\mathrm{P}<0.001)$. (B) $\mathrm{Patients}$ with low pretreatment plasma D-dimer level had longer PFS than patients with high pretreatment plasma $\mathrm{D}$-dimer level $(\mathrm{P}=0.001)$.

LDH level (> ULN), poor performance status (ECOG score 2-4), advanced stage (III-IV), more than 1 extranodal site, higher IPI (score 2-5) and higher NCCN-IPI $(\geq 4)$ among patients with DLBCL. These results were similar to those obtained by Liu et al. and Geng et al. $(16,17)$. Higher pretreatment plasma D-dimer level was an independent predictor of poor OS among patients with DLBCL, according to the univariate and multivariate analyses. This result was similar to that reported by Liu et al., but different from that reported by Geng et al. $(16,17)$. The optimal cut-off value of plasma D-dimer in our study $(1.4 \mu \mathrm{g} / \mathrm{mL})$ was approximately equal to that reported by Liu et al. $(1.6 \mu \mathrm{g} / \mathrm{mL})$ but much greater than that reported by Geng et al. $(0.92 \mu \mathrm{g} / \mathrm{mL})(16)$. The low cut-off value reported by Geng et al. might classify the subset of patients with DLBCL with low plasma D-dimer level and good prognosis into a group with high plasma D-dimer level, leading to a reduction in the discrimination efficiency of the cut-off value (16). Although higher pretreatment plasma $\mathrm{D}$-dimer level was negatively associated with PFS among patients with DLBCL, it was not an independent predictor of poor PFS. We believe that this could be because of the fact that the cut-off value was determined based on the OS of patients with DLBCL. Univariate analysis showed that other factors, including higher plasma LDH level (> ULN), poor performance status (ECOG score 2-4), advanced stage
(III-IV), more than 1 extranodal site, higher IPI (score 2-5), and higher NCCN-IPI $(\geq 4)$ were positively associated with poor OS and PFS among patients with DLBCL.

Owing to the larger sample size compared with that of other studies, the cut-off value of D-dimer level in our study was different from others, even though we determined it on the same basis as others $(16,17)$. However, from the results of our study and that reported by Liu et al., we can conclude that higher pretreatment plasma D-dimer level was an independent predictor of poor prognosis among patients with DLBCL. Therefore, it is necessary to derive a universal cut-off value for different cohorts of patients with DLBCL. Although abnormalities of coagulation and fibrinolytic factors have been proven to contribute to cancer progression, the mechanisms underlying how abnormal D-dimer levels affect the outcomes of patients with DLBCL remain to be investigated.

\section{Acknowledgments}

Funding: This work was supported by Fujian Provincial Medical Innovation Fund (grant number 2019-CX-15, 2017-CX-16), the Joint Funds for the Innovation of Science and Technology, Fujian province (grant number 2019Y9050, 2018Y9028), the University-Industry Cooperation Project of Fujian Science and Technology Department, Fujian, 
China (grant number 2018Y4004), Construction project of Fujian Medical Center of Hematology (Min201704) and National and Fujian Provincial Key Clinical Specialty Discipline Construction Program, China (22010301).

\section{Footnote}

Reporting Checklist: The authors have completed the REMARK reporting checklist. Available at http://dx.doi. org/10.21037/tcr-20-2908

Data Sharing Statement: Available at http://dx.doi. org/10.21037/tcr-20-2908

Conflicts of Interest: All authors have completed the ICMJE uniform disclosure form (available at http://dx.doi. org/10.21037/tcr-20-2908). The authors have no conflicts of interest to declare.

Ethical Statement: The authors are accountable for all aspects of the work in ensuring that questions related to the accuracy or integrity of any part of the work are appropriately investigated and resolved. The study was conducted in accordance with the Declaration of Helsinki (as revised in 2013). This study was approved by the ethics committee of Fujian Medical University Union Hospital (2019KJCX047) and individual consent for this retrospective analysis was waived.

Open Access Statement: This is an Open Access article distributed in accordance with the Creative Commons Attribution-NonCommercial-NoDerivs 4.0 International License (CC BY-NC-ND 4.0), which permits the noncommercial replication and distribution of the article with the strict proviso that no changes or edits are made and the original work is properly cited (including links to both the formal publication through the relevant DOI and the license). See: https://creativecommons.org/licenses/by-nc-nd/4.0/.

\section{References}

1. Swerdlow SH CE, Harris NL, et al. WHO Classification of Tumours of Haematopoietic and Lymphoid Tissues. Lyon, France: IARC Press, 2008.

2. Ayers EC, Li S, Medeiros LJ, et al. Outcomes in patients with aggressive B-cell non-Hodgkin lymphoma after intensive frontline treatment failure. Cancer 2020;126:293-303.
3. Crump M, Neelapu SS, Farooq U, et al. Outcomes in refractory diffuse large B-cell lymphoma: results from the international SCHOLAR-1 study. Blood 2017;130:1800-8.

4. Abdol Razak NB, Jones G, Bhandari M, et al. CancerAssociated Thrombosis: An Overview of Mechanisms, Risk Factors, and Treatment. Cancers (Basel) 2018;10:2091-2102.

5. Pabinger I, van Es N, Heinze G, et al. A clinical prediction model for cancer-associated venous thromboembolism: a development and validation study in two independent prospective cohorts. Lancet Haematol 2018;5:e289-98.

6. Falanga A, Russo L, Milesi V, et al. Mechanisms and risk factors of thrombosis in cancer. Crit Rev Oncol Hematol 2017;118:79-83.

7. Tawil N, Bassawon R, Rak J. Oncogenes and Clotting Factors: The Emerging Role of Tumor Cell Genome and Epigenome in Cancer-Associated Thrombosis. Semin Thromb Hemost 2019;45:373-84.

8. Magnus N, D'Asti E, Meehan B, et al. Oncogenes and the coagulation system--forces that modulate dormant and aggressive states in cancer. Thromb Res 2014;133 Suppl 2:S1-9.

9. Zhang C, Jia Y, Jia Y, et al. Prognostic and predictive value of plasma D-dimer levels in patients with small-cell lung cancer. Int J Clin Oncol 2018;23:1070-5.

10. Shiina Y, Nakajima T, Yamamoto T, et al. The D-dimer level predicts the postoperative prognosis in patients with non-small cell lung cancer. PLoS One 2019;14:e0222050.

11. Liu C, Ning Y, Chen X, et al. D-Dimer level was associated with prognosis in metastatic colorectal cancer: A Chinese patients based cohort study. Medicine (Baltimore) 2020;99:e19243.

12. Fan S, Zhao G, An G. High pretreatment plasma D-dimer levels are associated with shorter overall survival in patients with small cell lung cancer. J Int Med Res 2019;47:215-24.

13. Dirix LY, Salgado R, Weytjens R, et al. Plasma fibrin $\mathrm{D}$-dimer levels correlate with tumour volume, progression rate and survival in patients with metastatic breast cancer. Br J Cancer 2002;86:389-95.

14. Chen $\mathrm{Y}, \mathrm{Yu} \mathrm{H}, \mathrm{Wu} \mathrm{C}$, et al. Prognostic value of plasma D-dimer levels in patients with small-cell lung cancer. Biomed Pharmacother 2016;81:210-7.

15. Cao X, Kong YL, Wang L, et al. High plasma D-dimer level is a poor prognostic factor for patients with waldenstrom macroglobulinemia. Leuk Lymphoma 2020;61:1140-6.

16. Geng YD, Chen YR, Jin J, et al. Prognostic Value of D-Dimer in Patients with Diffuse Large B-cell 
Lymphoma: A Retrospective Study. Curr Med Sci 2019;39:222-7.

17. Liu B, Li B, Zhou P, et al. Prognostic value of pretreatment plasma D-dimer levels in patients with diffuse large B cell lymphoma (DLBCL). Clin Chim Acta 2018;482:191-8.

18. Cheson BD, Pfistner B, Juweid ME, et al. Revised response criteria for malignant lymphoma. J Clin Oncol 2007;25:579-86.

19. Hans CP, Weisenburger DD, Greiner TC, et al. Confirmation of the molecular classification of diffuse large B-cell lymphoma by immunohistochemistry using a tissue microarray. Blood 2004;103:275-82.

20. Horwitz SM, Zelenetz AD, Gordon LI, et al. NCCN Guidelines Insights: Non-Hodgkin's Lymphomas, Version 3.2016. J Natl Compr Canc Netw 2016;14:1067-79.

21. Zelenetz AD, Abramson JS, Advani RH, et al. NCCN Clinical Practice Guidelines in Oncology: non-Hodgkin's lymphomas. J Natl Compr Canc Netw 2010;8:288-334.

22. Zelenetz AD, Wierda WG, Abramson JS, et al. NonHodgkin's lymphomas, version 1.2013. J Natl Compr Canc Netw 2013;11:257-72.

23. Sehn LH, Berry B, Chhanabhai M, et al. The revised International Prognostic Index (R-IPI) is a better predictor of outcome than the standard IPI for patients with diffuse large B-cell lymphoma treated with R-CHOP. Blood 2007;109:1857-61.

24. Zhou Z, Sehn LH, Rademaker AW, et al. An enhanced International Prognostic Index (NCCN-IPI) for patients

Cite this article as: Huang H, Fan L, Fu D, Lin Q, Shen J. High pretreatment plasma D-dimer levels predict poor survival in patients with diffuse large B-cell lymphoma in the real world. Transl Cancer Res 2021;10(4):1723-1731. doi: $10.21037 /$ tcr-20-2908 with diffuse large B-cell lymphoma treated in the rituximab era. Blood 2014;123:837-42.

25. Deng Y, Chen X, Huang C, et al. EZH2/Bcl-2 Coexpression Predicts Worse Survival in Diffuse Large B-cell Lymphomas and Demonstrates Poor Efficacy to Rituximab in Localized Lesions. J Cancer 2019;10:2006-17.

26. Montalbán C, Díaz-López A, Dlouhy I, et al. Validation of the NCCN-IPI for diffuse large B-cell lymphoma (DLBCL): the addition of beta2 -microglobulin yields a more accurate GELTAMO-IPI. Br J Haematol 2017;176:918-28.

27. Montalbán C, Díaz-López A, Martín A, et al. Differential prognostic impact of GELTAMO-IPI in cell of origin subtypes of Diffuse Large B Cell Lymphoma as defined by the Hans algorithm. Br J Haematol 2018;182:534-41.

28. Larousserie F, Kebe D, Huynh T, et al. Evidence for IL-35 Expression in Diffuse Large B-Cell Lymphoma and Impact on the Patient's Prognosis. Front Oncol 2019;9:563.

29. Li X, Sun X, Li J, et al. Interim PET/CT based on visual and semiquantitative analysis predicts survival in patients with diffuse large B-cell lymphoma. Cancer Med 2019;8:5012-22.

30. Niu JY, Tian T, Zhu HY, et al. Hyperfibrinogenemia is a poor prognostic factor in diffuse large B cell lymphoma. Ann Hematol 2018;97:1841-9.

31. Shehata AMF, Aldesoky AI, Gohar SF. Plasma fibrinogen level as possible prognostic biomarker in diffuse large B-cell lymphoma. Hematology 2019;24:103-7. 